\title{
Role of the central R\&D laboratories of an international group in the field of Food-Feed Safety
}

Oléagineux, Corps Gras, Lipides. Volume 7, Numéro 5, 439-40, Septembre - Octobre 2000, Dossier : Sécurité sanitaire des aliments et industrie

Auteur(s): Katalin KOVARI, Cereol Group Center of Expertise Budapest, Kvassay 1, 1095 Budapest, Hungary.

Summary: With increased globalisation and more frequent crises within food/feed industry, public concern over food safety will remain at its present level and may even increase. The crushing/refining industry is likely to face further problems in the future. The recently established Food/Feed Safety Coordination Committee will be able to deal with any new crises at group level (communication, action organisation), in close cooperation with R\&D, which in turn will provide the scientific background, analytical results, proposals for technical solutions and continuous monitoring, for any given situation.

Keywords: food safety, polycyclic aromatic hydrocarbons dioxins.

\section{ARTICLE}

The mission of the Cereol R\&D Group is to serve the group with regard to the development of:

- new products,

- processes,

- analytical methods,

- nutritional information,

- scientific background in the field of food/feed safety;

and to ensure:

- safe products with high nutritional value and good, stable quality which meets the customers' needs,

- continuous development of applied industrial processes, which conserve the naturalness of the product as much as possible, and the removal of all unwanted compounds. 
Cereol Group has seven R\&D centers of expertise, each of them dedicated to a particular field of the group's activity (covering crushing, refining, analytical specialties, margarine and fats, olive oil, feed, packaging and non-food application) and has the experience, knowledge, human and analytical resources to meet the development and analytical needs to of the specified field.

All of these resources are incorporated into the quality assurance system and into handling and solving of food and feed safety problems.

\section{Quality assurance}

Production sites have their HACCP and ISO 9002 procedure. Control of raw materials and finished products are well defined.

The "traditional" quality variables are monitored in the factory laboratories but the determination of different contaminants requires specific, expensive analytical tools and experience, which are not available at the site. The central R\&D laboratories are responsible for systematically monitoring traces of contaminants as part of the quality assurance system.

For example, heavy metals, pesticide residues, polyaromatic hydrocarbon content are checked regularly for each production site. The results are summerized as a database.

The experts in the R\&D laboratories are working to improve method development through participation in international standardization (ISO, Codex Alimentarius, and CEN) and international ring tests.

The rapid development of analytical tools is ongoing and the group intends to equip the central laboratories with "state of art" instrumentalisation.

It has been decided that certain parameters such as radioactivity, dioxin, GMO will not be monitored "in house", but contracted out to certified laboratories.

\section{Food, feed safety}

The Cereol Group is committed to following the Fediol code of practice to reduce risk. Experts from R\&D and technical management are active participants in the Fediol activity and the accepted codes and recommendations are implemented in Cereol industrial practice.

\section{For example: procedure on polycyclic aromatic hydrocarbons (PAHs)}

A central monitoring system has been established.

The critical points have been identified e.g. geographical origin of the seed, risk of contamination, contamination level.

A Code of Practice has been implemented at all production sites.

The activated carbon products has been checked in the central laboratory to evaluate its effectiveness and required dosage. 
In cooperation with the central purchasing department, the best solution is defined.

Seed/oil purchasing department has been instructed to select reputable suppliers and to discourage unacceptable seed drying systems which are used in certain countries.

To extend our knowledge and to improve analytical capabilities Cereol R\&D laboratories regularly takes part in international ring tests (1998. Circular test on determination of benzo(a)pyrene content by HPLC, organised by Unilever; next ring test will be organised by Iterg for the determination of PAHs in near future).

\section{Another example: dioxin content of bleaching earth}

After recognizing possible risk, bleaching earth and the filter aid supplier have been checked. The central purchasing department has been provided with the summary of the survey.

The commercial contract for 2001 will contain the specification of the dioxin limit (less than $1 \mathrm{pg} / \mathrm{kg}$ TQE according to Fediol recommendation).

For monitoring, the suppliers' central laboratory collects samples from the products delivered and systematically checks the dioxin content using certified recognised laboratories.

\section{Best available technique}

Last but not least, another role of the Group R\&D activities is the continuous advancement of the knowledge and understanding of the risks and possible origin of the contaminants, in order to define the best available technique for removing them and to avoid the formation of unwanted components during storage and processing.

R\&D projects carried out in the field of process development aim to define the best technique. Newly developed processes and those that are currently in use are checked very carefully from the food safety point of view. Each process is evaluated for its effectiveness at removing contaminants (pesticide residues, heavy metals) and unwanted compounds (prooxidative metals, degradation products) and the risk of formation unwanted compound (trans fatty acids dimer, trimer, polymer). (For more details of our results see [1-4, 6].)

Equally importantly, we also focus on the preservation of the nutritional value of the product, to conserve the beneficial natural ingredients (tocopherols, sterols, essential fatty acids) as much as possible [5].

All of these results are taken into account in the decision - making process, as regards any new investment or reconstruction of a plant. 


\section{REFERENCES}

1. HÉNON G, KEMÉNY ZS, RECSEG K, ZWOBADA F, KÖVÁRI K (1997). Degradation of linoleic acid during heating. JAOCS, 74: 1615.

2. KÖVÁRI K, DENISE J, ZWOBADA F, KEMÉNY ZS, RECSEG K, HÉNON G (1997). Kinetic of trans isomer formation during heating. Paper presented at 22nd World Congress and Exhibition of the International Society for Fat Research. Kuala Lumpur, Malaysia.

3. HÉNON G, KEMÉNY ZS, RECSEG K, KÖVÁRI K (1999). Deodorization of vegetable oils. Part 1: Modelling the geometrical izomerization of polyunsaturated fatty acids. JAOCS, 76: 73.

4. HÉNON G (2000). Modèle prédictif de l'isomérisation trans des acides gras polyinsaturés au cours de la désodoration industrielle des huiles végétales. $O C L, 7: 91$.

5. KÖVÁRI K (2000). Physical refining of sunflower oil. OCL, 7: 305-8.

6. RECSEG K, KÖVÁRI K, KEMÉNY ZS, DENISE J (1998). Effect of crude oil quality and refining process on the polymerized and oxidized trygliceride content. Paper presented at 52nd DGF Congress. Magdeburg, Germany. 